\title{
Digital Transformation of Healthcare
}

\author{
Serik Smagulov, \\ Viktoriya Smagulova MD
}

\begin{abstract}
In a situation where digital corporations are switching to healthcare, the state obliges medical institutions to constantly improve the quality of services provided, and patients seek high-quality care, which has serious implications for the healthcare sector. The purpose of the study was to understand the growing role of digitalization of health care, based on the experience of western countries, to consider the benefits and identify possible problems faced by medical institutions and their patients. As a result of the study, it was revealed that digital transformation makes it possible to improve the efficiency of healthcare by reducing costs and improving the quality of medical care.
\end{abstract}

Key words: Digital transformation, digitalization, personal data, health information, patient information, communication, diagnostic tools, transformation, healthcare.

Society is getting older, and health care costs continue to grow. It is assumed that the digitalization of medical services can be presented with lower costs and higher quality.

In Austria there is ELGA, an electronic medical record system that any doctor or hospital can easily access as needed. Doctors in Sweden, Denmark and Estonia send the prescriptions to the patient electronically or directly to the pharmacy that delivers the drugs. The British NHS is working with Google to deploy artificial intelligence in the medical field [1].

Digital transformation and disruptive innovation describe the comprehensive reorientation of an industry including its business models due to the coming of age of digital technologies: the digitization of products, services, and processes [2].

It is assumed that digitization will provide faster access to data.

Another advantage of the digital transformation of healthcare is paperless data which includes a unified electronic record and the exchange of health information. In this case, records and storage of all patient information should be available from any medical institution. The electronic appointment, the digital version of the prescription drug, is transmitted to the pharmacy in real time. Recipe data can be used to automatically check, for example, side effects. 
Digital transformation of healthcare provides in-patient communication with staff. This refers to software that allows communication between hospital staff and coordinating its work.

Teleconsultation becomes important nowadays: tools that provide remote interaction between the doctor and patient, especially for small requests or subsequent consultations. It is especially important to conduct remote monitoring of patients with chronic diseases. Most often it is the monitoring of vital parameters of patients at high risk of developing chronic diseases.

Modern digital diagnostic tools are technologies that allow remote diagnostics [3].

Recent modern developments in the digital transformation of healthcare include:

- Use of bar codes: error-free barcode-based identification and confirmation of all prescribed drugs in the ward where the patient is located.

- Radio Frequency Identification (RFID) tracking: spatial tracking of all assets (for example, diagnostic tools, beds, expensive medicines) using RFID technology.

- Vital Parameters Tracking (eICU): remote monitoring of vital signs in the intensive care unit.

- Hospital logistics using robotics: robots that perform repetitive tasks (for example, transporting drugs / patients).

- Automation of processes with the help of robots: the use of robotics to perform simple tasks (for example, monitoring vital signs, processing samples).

- Electronic directions: Referral and discharge information (including test / clinical data) is sent to the next doctor for patient consultation.

- Dashboards to improve performance: to increase the internal availability of data on the doctors work.

- Software to manage the patients flow.

- Genetic testing: individual treatment decisions are made on the basis of patientspecific genomic, proteomic and other data. 
- Technologies for the treatment of chronic diseases.

- Programs for patients with diabetes: reminders to patients about compliance with the treatment regimen; connected insulin testing devices [4].

- Online programs of pulmonary rehabilitation for patients with respiratory diseases; connected inhalers.

- Education of patients with cardiovascular diseases: the use of connected sensors / heart rate monitors with alert function.

- Medical chat bots: completely based on artificial intelligence or controlled by special applications.

- Tools for disease prevention: applications, virtual trainers and fitness trackers.

In Europe there has long been an electronic registration system through online portals that allow patients to schedule their own meetings with general practitioners (GP) and specialists. They are also connected to the reminder function.

As for the European health care system, there is a significant financial cost savings when introducing the digital transformation of healthcare. The greatest savings can be expected from the transition to unified electronic medical records, which represents a potential savings of 6.4 billion euros (19 percent). The savings consist in the subsequent increase in productivity and efficiency. For example, by reducing the time required for administration and reducing the number of unnecessary duplicate actions.

The virtual features of the digital platform are particularly useful in remote areas, where the number of locally registered medical specialists is limited. The digital solution represents nurses and doctors, full access to patient information, wherever they work, and allows them to record their results on a tablet [5].

Digital transformation is not just a transformation of the work of doctors and nurses; it also gives patients the opportunity to manage their treatment independently and share data with their doctors.

Professional health care market participants can have serious problems. First of all, control is needed for the introduction of electronic medical records and electronic 
prescriptions. It is important that medical records provide open interfaces between online and offline treatment and that patients can maintain absolute control over the personal data that is created and transmitted [6].

It should be noted that there are no tools in the health care industry to ensure real responsibility. For example, when clients make an appointment with a doctor, they do not have the opportunity to know in advance about the successes or failures of this health care provider. Medical companies need a standard set of procedures for handling patient feedback.

Digital transformation in healthcare helps ensure financial transparency. Technology can help the industry provide customers with more information on health spending.

Digitization paves the way for new approaches to medicine and provides opportunities for solving some health problems. While some privacy concerns remain, patients are already taking advantage of digital medical solutions, such as online services and online tools. Using digital solutions can also help make the system more efficient and establish a more integrated approach.

Despite new technologies being constantly introduced, this change has yet to materialize [7-8].

The process of digital transformation in health care should not be limited to the technologies necessary for innovation. It is also necessary to attract specialists.

Indeed, digital transformation has already revolutionized all industries, but it is in the healthcare sector that technologies help us live longer and lead safer, healthier, and more productive lives.

\section{References}

1. Steffen Hehner, Stefan Biesdorf, Martin Möller. Digitizing healthcare-opportunities for Germany // McKinsey on Healthcare. October. 2018.

2. Harvard Business Review. 2014 Oct 01. Digital transformation in the high-tech industry: briefing paper sponsored by SAP URL:

https://hbr.org/resources/pdfs/comm/sap/18764_HBR_SAP_High_Tech_Aug_14.pdf

3. Steinhubl SR, Muse ED, Topol EJ. Can mobile health technologies transform health care? JAMA 2013 Dec 11;310(22):2395-2396. [CrossRef] [Medline] 
4. Kaufman N, Salahi A. Using digital health technology to prevent and treat diabetes. Diabetes Technol Ther 2017 Feb;19(S1):S59-S73. [CrossRef] [Medline]

5. Kohn LT, Corrigan JM, Donaldson MS, editors. To Err is Human: Building a Safer Health System. Washington: National Academies Press; 2000.

6. McGrail KM, Ahuja MA, Leaver CA. Virtual visits and patient-centered care: results of a patient survey and observational study. J Med Internet Res 2017 May 26;19(5):e177 [FREE Full text] [CrossRef] [Medline]

7. Perakslis ED. Strategies for delivering value from digital technology transformation. Nat Rev Drug Discov 2017 Feb;16(2):71-72. [CrossRef] [Medline]

8. Westerman G, Tannou M, Bonnet D, Ferraris P, McAfee A. The digital advantage: how digital leaders outperform their peers in every industry. URL: http://digitalcommunity. mit.edu/servlet/JiveServlet/downloadBody/1105-102-2-1185/

The_Digital_Advantage_How_Digital_Leaders_Outperform_their_Peers_in_Every_Industr y.pdf [accessed 2017-11-08] [WebCite Cache] 